\title{
Mysteries of Monozygosity: Theories and Breakthroughs/Twin Research: Rare Case of Lost Twins; Developing a National Twin Registry; Twins' Language and Gesture Delays; DNA Testing for Vanishing Twins/Media Reports: Identical Twins Discordant for COVID Vaccination; World's Oldest Identical Twins; Olympic Athlete Stand-in; Fraternal Twin Football Players
}

\author{
Nancy L. Segal \\ Department of Psychology, California State University, Fullerton, CA, USA
}

\begin{abstract}
The processes that give rise to monozygotic (MZ) twins remain elusive. This article describes various theories of MZ twinning that have been examined over the years, although they continue to be speculative. It has also been impossible to know if a singleton began life as an MZ twin; however, a critical technological breakthrough can now reveal this important birth history information with a high degree of certainty. The section that follows presents reviews of current research regarding rare twin loss, development of a twin registry, twins' communicative delays and DNA testing for vanishing twins. The article concludes with a survey of newsworthy twins, namely identical twins discordant for COVID vaccination, the world's oldest identical twins, an Olympic athletic stand-in and fraternal twin football players.
\end{abstract}

\section{Mysteries of Monozygosity: Theories and Breakthroughs}

Whether all cases of Amyoplasia began as MZ twins and are related to TTT [twin-to-twin transfusion] awaits a molecular method to identify surviving MZ twins and possibly animal experiments producing TTT. (Hall, 2021a, p. 1820)

Our study also demonstrates a never-anticipated corollary: because identical twins keep a lifelong molecular signature, we can retrospectively diagnose if a person was conceived as monozygotic twin. (von Dongen et al., 2021, p. 1).

\section{Theories: What Causes MZ Twinning?}

The processes giving rise to monozygotic (MZ) twinning remain elusive despite twins' popularity as participants in behavioral and medical research. Various theories have been proposed to account for the early division of the zygote, an event that occurs in approximately .3-.4\% of births worldwide (see Segal, 2017). Blickstein $(2005,2020)$ and Blickstein and Keith (2007) have surveyed four possible explanatory interpretations (among others) for why MZ twinning takes place: (1) Cell repulsion hypothesis: Developmental differences between adjacent cells might cause repulsion, leading to zygotic division; (2) Co-dominant axes:

Author for correspondence: Nancy L. Segal, Email: nsegal@fullerton.edu

Cite this article: Segal NL. (2021) Mysteries of Monozygosity: Theories and Breakthroughs/Twin Research: Rare Case of Lost Twins; Developing a National Twin Registry; Twins' Language and Gesture Delays; DNA Testing for Vanishing Twins/ Media Reports: Identical Twins Discordant for COVID Vaccination; World's Oldest Identical Twins; Olympic Athlete Stand-in; Fraternal Twin Football Players. Twin Research and Human Genetics 24: 408-412, https://doi.org/10.1017/thg.2021.51
Two embryonic axes form and continue to develop, possibly causing the zygote to split; (3) Depressed embryonic calcium levels: Decreased calcium levels weaken intercellular bonding, yielding MZ twins; and (4) Blastomere herniation hypothesis: A hatching event occurs, due to an opening in the zona pellucida (the layer surrounding mammalian ova and preimplanted embryos; Wassarman et al., 1999), herniation of the blastomeres (cells produced by division of the zygote; Bio-Medicine, 2012) and zygotic splitting. The fourth and most widely cited hypothesis was suggested by the increased MZ twinning observed when women undergo an assisted reproductive technology (ART) procedure. Specifically, the hatching is thought to result from micromanipulation of the zygote, although this would not explain higher-order MZ multiple birth sets unless there were additional breaks in the zona pellucida. It is also possible that ovulation induction, rather than micromanipulation, is responsible for MZ twinning events (Blickstein, 2020).

The observed association between MZ twinning and disorders linked to genomic imprinting has also been intriguing. For example, there is an excess of MZ twins discordant for BeckwithWiedemann syndrome (BWS), a condition in which affected individuals grow taller than their peers until approximately eight years of age. Some children also show excess growth in some areas of the body, and $10 \%$ may be at risk for cancers and tumors (Medline Plus, 2020). The gene responsible for this condition is autosomal dominant and can be transmitted by the mother or the father. However, approximately $20 \%$ of affected children have inherited a particular gene from their father that is active; a change in the relevant gene increases the risk, albeit to an unknown degree. 
If the same gene change occurs in the mother, the risk of having an affected child is $50 \%$ (ThinkGenetic, 2016).

It is possible that an imprinting defect occurred at a crucial moment prior to implantation of the fertilized egg and that the defect caused it to divide, resulting in MZ twins. It is also possible that events that caused the zygote to separate also caused one twin to have a defect in the BWS gene (Segal, 2017; Weksberg et al., 2002). Skewed $X$ chromosome inactivation and 'overripe ova' have also been proposed as explanations for why MZ twinning occurs (Hall, 1996, 2003, 2021b). Interestingly, Hall reports that delayed fertilization has been linked to MZ twinning in rabbits, roe deer and frogs. Also revealing is an excellent comprehensive review of 'recurrent constellations of embryonic malformations' (RCEMs). These malformations were recast as (1) primary malformations of presumed embryonic origin and (2) structural defects defined as malformations or disruptions due to prenatal problems in vascular perfusion (blood flow and gas exchange) or hemorrhage. A literature search by the authors yielded RCEMs involving six different systems or conditions, for example, limb-body wall complex and imperforate anus-spinal defects. There was an excess of affected MZ twins and $80 \%$ discordance across all twins for the six malformations affecting embryonic development (Adam et al., 2020).

\section{MZ Twins: More Than Just One Type}

Hall (2021b) has recognized three types of MZ twinning in humans and summarizes their key characteristics in an informative table: (1) Spontaneous: This type of twinning seems to occur with the same frequency worldwide, that is, $1 / 250$ births. Hall explains this event by implicating 'overripe ova', given findings from nonhuman animal studies and unique human sexual practices. She reasoned that overripe eggs may not function normally, leading to atypical development. Conjoined twins and twins showing mirror-imaging effects would fall into this category. (2) Familial: This type of twinning may relate to an aberrant protein (of maternal origin) in the zona pellucida, causing early rupture, problems with cell adhesion (of maternal or paternal origin) and cells coming apart. Skewed X-inactivation would be classified in this category. A family history of twinning would be evident and would include higher-order multiples. (3) ART-related: This type of twinning has been explained by manipulation of the zona pellucida, hardened zona due to freezing or culturing, a thin zona or some unspecified deficiency. Hall also invoked the 'overripe ova' hypothesis here, given that the ova have been frozen or stored.

The fertility drug clomiphene citrate (clomid) has also been associated with MZ twinning (Alkilnai et al., 2003; Derom et al., 2006). An earlier link between clomid and polar body twinning has also been reported (Fischer, 1990; Fischer \& Polesky, 1979).

\section{Breakthrough 2021}

The latest insight into the mysteries of monozygosity comes from a 2021 paper led by Jenny van Dongen of the Free University in Amsterdam and co-authored with participants in the Genetics of DNA Methylation Consortium that include ISTS members and the Twin Research and Human Genetics editor, Professor Nick Martin (von Dongen et al., 2021). It was discovered that MZ twins carry a set of markers ('stable DNA methylation signature') near certain chromosomal regions (telomeres and centromeres). Using this information, they demonstrated it was possible to identify MZ twins using different study samples and different biological materials, with probabilities ranging from
.77 to .80 . It was suggested that events surrounding cell adhesion may explain why the fertilized egg divides in some cases. Associations among these 'signatures', imprinting processes and known birth defects were not found, but offer a promising path to discovery.

Asked to comment on this paper prior to its release, I indicated that it was 'absolutely fascinating' (Lambert, 2021). Scientists are captivated by twins, not just with what they reveal about human behavioral and physical development but also with the problems and questions remaining to be solved - and what causes MZ twinning to occur has been elusive for years. Therefore, it is not surprising that this research generated intense interest worldwide. I believe that the implications of this work reach beyond what even the authors may have envisioned. Specifically, identifying MZ twins is a first step in the quest for refining knowledge of twinning processes and the origins of certain birth defects and medical conditions.

This newest discovery regarding $\mathrm{MZ}$ twin identification has applied significance. It can help solve cases involving reared-apart MZ twins, switched-at-birth MZ twins, kidnapped twins and individuals who believe that their psychological problems stem from losing an alleged cotwin during the prenatal period. Newly uncovered evidence that deceased historical figures or family members were part of an identical twin pair might prompt investigation of their remains. In fact, I am aware of a book-length manuscript offering evidence that Louis XIV had an identical twin brother (Madry, 2021). The author, who describes her work as 'a detective story that science helps solve', would be interested in cooperating with French twin researchers, geneticists and/or forensic specialists to examine the remains for evidence of an $\mathrm{MZ}$ twin signature. I can provide the author's contact information upon request. Other circumstances in which identifying MZ twins may prove useful will most certainly arise.

\section{A Matter of Time}

In concluding this part of the article, it is important to comment on the widely accepted relationship between the timing of zygotic division and chorionicity/placentation. As I have indicated elsewhere (Segal, 2017), the belief that earlier splitting yielded separate placenta and membranes was seriously challenged by the Spanish physician, Gonzalo Herranz (2013/2015). He cited a 1922 paper in which this model was proposed by the American anatomist and embryologist, George W. Corner (1922). Corner developed his ideas further in 1955, while acknowledging their theoretical nature (Corner, 1955). However, Herranz explained the general acceptance of this model by noting that (1) Corner was a prestigious investigator; (2) the model appeared plausible; and (3) Corner's original diagram and adaptations made the model seem correct to his colleagues. In recent years, this model has been questioned by some scientists (including me), but is still cited frequently in the scientific literature on twins (Segal, 2017).

Science moves forward. I believe that one day researchers will discover the true relationships between zygotic division and chorionicity/placentation. We may be surprised.

\section{Twin Research}

\section{Rare Case of Lost Twins}

The COVID-19 pandemic has raised serious health concerns among pregnant women and their physicians. Specifically, the possibility of adverse effects from the virus on the mother and/or 
fetuses has attracted attention. Researchers in Belgium reported two cases of rare fetal loss in virus-infected women, one of whom was carrying twins (Libbrecht et al., 2021). The 22-year-old primipara was seen by physicians at the 36th gestational week at which time she showed severe eclampsia and ruptured membranes. She had tested positive for COVID-19 the week before, but her symptoms were mild. Unfortunately, one twin suffered intrauterine fetal death and the other was in extreme distress and could not be saved. It was determined that neither twin was affected by the virus. It was concluded that in the twins' case, COVID-19 infection of the placenta led to necrosis of the trophoblast (cells attaching the zygote to the uterine wall that later form part of the placenta; Medical Dictionary, 2021), which damaged the twins. The nontwin case was similar to that of the twins, but the trophoblast necrosis was less severe, and the pregnancy proved successful.

\section{Developing a National Twin Registry}

Researchers in Tehran have created a conceptual framework for establishing a national twin registry (Abtahi et al., 2021). Their study, which was qualitative and descriptive, included (1) a literature review, (2) focus groups to assemble the viewpoints of twin research experts, (3) analysis of themes and synthesis of findings, and (4) mapping the results and designing the model. They used the Consolidated Criteria for Reporting Qualitative Research (COREQ) to manage their findings. The COREQ is a 32-item checklist that assists researchers undertaking such projects (Tong et al., 2007). The literature review, which was limited to English-speaking countries, initially yielded 607 articles, but only 46 were included in the study after accounting for duplication and relevance. Information was drawn from registries in 24 countries located in North America, South America, Europe, Asia and Australia. It was determined that $79 \%$ of the registries were national and $21 \%$ were provincial; the provincial registries were situated in the United States.

The authors suggested that their model could be used for the further understanding and establishment of twin registries. They indicated that devising the best strategic plan in the beginning is paramount since this affects the unfolding of events that follow. The greatest challenges that they confronted were identifying twins and gathering health-related data. The authors claim that failure to overcome these difficulties has prevented the development of twin registries in many countries.

\section{Twins' Language and Gesture Delays}

There is a large literature on twins' well-known language delays, but relatively less on their use of gestures, especially in toddler twins. A recent study by Foran et al. (2021) examined both verbal and nonverbal communication in 44 twin pairs, representing $64 \%$ of the 69 families who agreed to participate; however, 25 families did not provide complete data. The twin children in the final sample had an adjusted mean age of 16.5 months $(S D=0.55)$ with an age range of 15 to 17 months. Information was provided by mothers who completed the MacArthur-Bates Communicative Development Inventories, second edition: Words and Gestures.

Not surprisingly, the twins showed the expected lag in receptive and expressive language that has been reported in other twin studies. However, the researchers were surprised that depressed development was higher for gesturing than for speech; 29 twin pairs fell below the norm. I also found this surprising, given the general belief that twins often communicate nonverbally with one other, thus contributing to their verbal deficit. It is possible that gesturing is used more often among older children.

Unfortunately, the researchers did not explain their methods for zygosity assessment, but indicated that 32 pairs were dizygotic (DZ), 8 pairs were MZ, and 4 pairs were of unknown type. Another problematic feature of this paper is that while communicative delays were linked to the 'twinning effect', this term was not clearly defined. Finally, communicative difficulties were not examined with reference to zygosity, despite citing research showing that $\mathrm{MZ}$ twins are at greater communicative risk than DZ twins; however, the findings are mixed in this regard. The authors explained that 'our purposes were not to compare epidemiological factors for monozygotic and dizygotic or singleton births. Instead, we were interested in how twins would present with regard to risk factors for DLD (developmental language disorder) using a clinical tool combined with case history details' (p. 333).

Foran et al. (2021) indicated that the only other study of twins' gestures (Aldrich et al., 2015) found that twin toddlers were more likely to use showing gestures and other communicative/ interactive behaviors with their mothers than with their twin siblings. Here again, it is unfortunate that the zygosity of the participating pairs was not established by standard means; the eight same-sex pairs could have been MZ or DZ. A group of nontwins was not included, but would have been informative in regard to the comparative frequency of nonverbal behaviors.

\section{DNA Testing for Vanishing Twins}

Cell-free fetal DNA testing (cfDNA) uses cell-free placental DNA from the mother's bloodstream. Balaguer et al. (2020) note that cfDNA could potentially become a standard screening procedure for aneuploidies during the first trimester of pregnancy. To test the feasibility of the procedure, they retrospectively examined 25,080 consecutive pregnancies undergoing cfDNA testing for fetal aneuploidy with reference to chromosomes 13, 18, 21 and sex chromosomes. The data were obtained from the Prenatal Department of Igenomix Spain Laboratory S.L.U. There were 24,874 nontwin cases and 206 vanishing twin cases.

The prevalence of positive cases, sex discrepancies and false positives was higher for vanishing twins than for singletons ( $5.8 \%$ vs. $2.5 \%, 10.2 \%$ vs. $0.05 \%$ and $2.6 \%$ vs $.3 \%$ respectively). After the 14th gestational week, the incidence of these measures declined. It was suggested that cfDNA analysis should be used with vanishing twins, given its advantage of being a noninvasive procedure. It was also recommended that it be applied after week 14 to avoid false-positive findings, although further research is warranted. The potential to test epigenetic signatures to identify $\mathrm{MZ}$ twins and MZ twin survivors from the vanishing twin syndrome, is raised by this method.

\section{Media Reports}

\section{Identical Twins Discordant for COVID-19 Vaccination}

It is unusual to find identical twins discordant for having the COVID-19 vaccination, but Billy and Bobby Ford are such a pair (Reisman, 2021). The twins, who were originally from Williamsburg, Virginia, have been close brothers their entire lives. In 1993, Bobby opened Bobby's Auto Service Center in Vero Beach, Florida, where Billy later joined him. However, Bobby could not persuade his twin to become vaccinated because Billy believed in the conspiracy theories surrounding the virus that were circulating through the media. The twins were also discordant for 
diabetes that Billy developed later in life — both twins were six feet, three inches tall, but Billy started weight reduction medications when he reached 400 pounds and Bobby (who was unaffected with diabetes) reduced his weight from 320 pounds to 240 pounds. Obesity is a risk factor for both diabetes and COVID-19 infection.

One of the twins' coworkers contracted the virus, and eventually, the employees became infected. Bobby showed minor symptoms, whereas Billy required hospitalization. Billy finally admitted that he wished he had been vaccinated, but it was too late - sadly, he passed away on August 14, 2021, at age 59. His twin brother Bobby said, 'A twin is your best friend and your worst enemy. You have someone that looks just like you competing for the same friends, the same girls, the same everything. You know, it is fine for me to punch you, but nobody else.'

\section{World's Oldest Identical Twins}

The Guinness World Book recognized an identical pair, Umeno Sumiyama and Koume Kodam, as the oldest twins on record (Mitchell, 2021). These identical twin sisters were born on November 3, 1913, earning their new title at the age of 107 years and 330 days. The announcement took place on Japan's national holiday, Respect for the Aged Day. The previous record holders were Kin Narita and Gine Kanie, also from Japan, who acquired their distinction at the age of 107 years and 175 days.

Umeno and Koume were the third and fourth children of an eleven-child family. As youngsters, they experienced bullying because of prejudices against multiple birth individuals. Perhaps that is why the twins grew up apart - they were separated in elementary school when Umeno went to the southern Japanese island of Kyushu to work as a maid and Koume remained on their native island of Shodoshima and raised a family. When the two turned 70 years old, they began meeting periodically and visiting shrines together.

It is worth noting that Tanaka Kane, the world's oldest living person at 118 years of age, is from Japan. In addition, the oldest living man on record is Jiroemon Kimura, also from Japan, who lived for 116 years and 54 days. Over one-fourth (29\%) of Japan's 125 million residents are at least 65 years old. Among this group, about 86,510 are centenarians, half of whom turned 100 in 2021. Twin and nontwin studies of factors affecting longevity in Japan would be worth pursuing.

\section{Olympic Athlete Stand-In}

The 'Brief News' section of Time Magazine (2021) reported that identical Puerto Rican twins, Madeline and Margaret de Jeus, were eliminated from the 1984 Olympic 4 x 400 relay (Time Magazine, 2021). The reason was that Madeline had taken her sister's place after Margaret had been injured. Events leading to this discovery were not indicated by Time, but I found answers elsewhere (Tomizawa, 2017). Madeline had injured her hamstring in an earlier long jump competition and knew she could no longer compete. Her identical twin sister was a spectator and also a sprinter who did not qualify for the competition. No one knew of Madeline's injury, so the sisters arranged to have Margaret take her place. The deception was detected when a Puerto Rican journalist who had covered the sister's athletic careers knew that only one twin had a beauty mark on her cheek and realized that the wrong twin was on the track.

\section{Fraternal Twin Football Players}

Micah and Malachi Partee are fraternal twins who play for the Rams at Kennard-Dale High School in Fawn Grove, Pennsylvania (Allibone, 2021). Their different height and weight qualify them for different positions on the football team. Micah, a running back, is five feet, seven inches tall and weighs 185 pounds; Malachi, an offensive tackle, is six feet tall and weighs 235 pounds. The twins are considered the stars of the team, leading the Rams to its best season in years. The team is part of the York Adams Interscholastic Athletic Association.

The twins' family has a football history. Their father played football for Moorhouse College in Atlanta, Georgia, and their older brother Marc played defensive line for the Rams. Marc has helped prepare Micah and Malachi to be more successful in their careers than he. The twins are now thinking about college where they will continue to play football. Off the field, Micha hopes to become a journalist and Malachi, who has the highest grade point average of his teammates, plans to become a physical therapist and earn a doctorate. Their parents want them to attend the same school, but the twins think some separation may be helpful despite their close ties. Having different interests and talents is characteristic of most fraternal twins (Segal, 2017).

\section{References}

Abtahi, H., Gholamzadeh, M., Shahmoradi, L., \& Shariat, M. (2021). An information-based framework for development national twin registry: Scoping review and focus group discussion. The International Journal of Health Planning and Management, 36, 1423-1444.

Adam, A. P., Curry, C. J., Hall, J. G., Keppler-Noreuil, K. M., Adam, M. P., \& Dobyns, W. B. (2020). Recurrent constellations of embryonic malformations re-conceptualized as an overlapping group of disorders with shared pathogenesis. American Journal of Medical Genetics Part A, 182, 2646-2661.

Aldrich, N. J., Brooks, P. J., Yuksel-Sokmen, P. O., Ragir, S., Flory, M. J., Lennon, E. M., Karmel, B. Z., \& Gardner, J. M. (2015). Infant twins' social interactions with caregivers and same-age siblings. Infant Behavior and Development, 41, 127-141.

Alikani, M., Cekleniak, N. A., Walters, E., \& Cohen, J. (2003). Monozygotic twinning following assisted conception: An analysis of 81 consecutive cases. Human Reproduction, 18, 1937-1943.

Allibone, M. (2021, September 27). One's big. One's small. How these not-so-identical football twins lead in different ways. York Daily Record. https://www.ydr.com/story/sports/high-school/football/2021/09/27/kennarddale-how-twins-micah-and-malachi-partee-lead-different-ways/5850491001/

Balaguer, N., Mateu-Brull, E., Serra, V., Simón, C., \& Milán, M. (2020). Should vanishing twin pregnancies be systematically excluded from cell-free fetal DNA testing? Prenatal Diagnosis, 41, 1241-1248.

Bio-Medicine. (2012). Blastomere. http://www.bio-medicine.org/biologydictionary/Blastomere/

Blickstein, I. (2005). Estimation of iatrogenic monozygotic twinning rate following assisted reproduction: pitfalls and caveats. American Journal of Obstetrics and Gynecology, 192, 365-368.

Blickstein, I. (2020). Biology of monozygotic twinning. In A. Matias \& I. Blickstein (Eds.), Why are monozygotic twins different: From genetics to environment (pp. 7-58). Elsevier.

Blickstein, I., \& Keith, L. G. (2007). On the possible cause of monozygotic twinning: Lessons from the 9-banded armadillo and from assisted reproduction. Twin Research and Human Genetics, 10, 394-399.

Corner, G. W. (1922). The morphological theory of monochorionic twins as illustrated by a series of supposed early twin embryos of the pig. Johns Hopkins Hospital Bulletin, 33, 389-392.

Corner, G. W. (1955). The observed embryology of human single-ovum twins and other multiple births. American Journal of Obstetrics and Gynecology, 70, 933-951. 
Derom, C., Leroy, F., Vlietinck, R., Fryns, J. P., \& Derom, R. (2006). High frequency of iatrogenic monozygotic twins with administration of clomiphene citrate and a change in chorionicity. Fertility and Sterility, 85, 755-757.

Fischer, K. (1990). A rapid evolution mechanism may contribute to changes in sex ratio, multiple birth incidence, frequency of auto-immune disease and frequency of birth defects in clomid conceptions. Medical Hypotheses, 31, 59-65.

Fisher, K. M., \& Polesky, H. F. (1979, October). Polar body conceptions and fertility drug twins [Paper presentation]. American Society of Human Genetics, Minneapolis.

Foran, L. G., Evans, K. J., \& Beverly, B. L. (2021). Assessing language delay in twins: Low gesture use and birth history factors. Infants \& Young Children, $34,324-336$.

Hall, J. G. (1996). Twins and twinning. American Journal of Medical Genetics, $61,202-204$.

Hall, J. G. (2003). Twinning. The Lancet, 362, 735-743.

Hall, J. G. (2021a). The mystery of monozygotic twinning I: What can Amyoplasia tell us about monozygotic twinning and the possible role of twin-twin transfusion? American Journal of Medical Genetics Part A, 185, 1816-1821.

Hall, J. G. (2021b). The mystery of monozygotic twinning II: What can monozygotic twinning tell us about Amyoplasia from a review of the various mechanisms and types of monozygotic twinning? American Journal of Medical Genetics Part A, 185, 1822-1835.

Herranz, G. (2013/2015). The timing of monozygotic twinning: A criticism of the common model. Zygote, 23, 27-40.

Lambert, J. (2021, September 28). All identical twins may share a common set of chemical markers on their DNA. Science News. https://www. sciencenews.org/article/identical-twin-siblings-common-set-chemical-markersdna-epigenetics

Libbrecht, S., Van Cleemput, J., Vandekerckhove, L., Colman, S., Padalko, E., Verhasselt, B., van de Vijver, K., Dendooven, A., Dehaene, I., \& van Dorpe, J. (2021). A rare but devastating cause of twin loss in a near-term pregnancy highlighting the features of severe SARS-CoV-2 placentitis. Histopathology, 79, 674-676.

Madry, S. B. (2021). Second Son, the Man in the Iron Mask. [Manuscript in preparation].

Medical Dictionary. (2021). Trophoblast. https://medical-dictionary.thefree dictionary.com/trophoblast

Medline Plus. (2020). Beckwith-Wiedemann syndrome. http://ghr.nlm.nih. gov/condition/beckwith-wiedemann-syndrome
Mitchell, C. (2021, September 20). Two Japanese sisters have become the world's oldest identical twins just 15 days shy of their 108th birthday. Daily Mail. https://www.dailymail.co.uk/news/article-10009367/Two-sistersworlds-oldest-identical-twins-just-15-days-shy-108th-birthday.html

Reisman, L. (2021, September 6). Identical twins: One was vaccinated for COVID, the other wasn't; How'd they fare? Yahoo News. https://news.yahoo. com/identical-twins-one-vaccinated-covid-120027957.html?guccounter= 1\&guce_referrer=aHR0cHM6Ly93d3cuZ29vZ2xlLmNvbS8\&guce_referrer_ sig=AQAAABseCflpOFHD0sFLEpQBeChvgQK7jywsiZgrdCx5mXqEq_jCZQ ehOClqHJnFRou85YvYYCEXOGGJiB8KBLTbVf2kgNLehMoVB7Uvaov 5T3EE_ZDmOjTp4fx5AXDNklLLIAfU9rebG4jk0BB4OWJdHrYi0NlSz-_ 4h2e9efkNtya0

Segal, N. L. (2017). Twin mythconceptions: False beliefs, fables, and facts about twins. Elsevier.

Think Genetic. (2016). Beckwith-Wiedeman syndrome. https://www.think genetic.com/diseases/beckwith-wiedemann-syndrome/inheritance/17458

Time Magazine. (2021). Seeing double. Time Magazine, 198, 14.

Tomizawa, R. (2017, November 6). The tale of Madeline and Margaret de Jesus: Twins who almost got away with it at the 1984 Los Angeles Olympics. The Olympians. https://theolympians.co/2017/11/06/the-tale-of-madeline-andmargaret-de-jesus-twins-who-almost-got-away-with-it-at-the-1984-losangeles-olympics/

Tong, A., Sainsbury, P., \& Craig, J. (2007). Consolidated criteria for reporting qualitative research (COREQ): A 32-item checklist for interviews and focus groups. International Journal for Quality in Health Care, 19, 349-357.

van Dongen, J., Gordon, S. D, McRae, A. F., Odintsova, V. V., Mbarek, H., Breeze, C. E., Sugden, K., Lundgren, S., Castillo-Fernandez, J. E., Hannon, E., Moffitt, T. E., Hagenbeek, F. A., van Beijsterveldt, C. E. M., Jan Hottenga, J., Tsai, P.-C., Hottenga, J.-J., de Geus, E. J. C., Spector, T. D., BIOS Consortium; Genetics of DNA Methylation Consortium, ... Boomsma, D. I. (2021). Identical twins carry a persistent epigenetic signature of early genome programming. Nature Communications, 12, 5618.

Wassarman, P., Chen, J., Cohen, N., Litscher, E., Liu, C., Qi, H., \& Williams, Z. (1999). Structure and function of the mammalian egg zona pellucida. Journal of Experimental Zoology, 285, 251-258.

Weksberg, R., Shuman, C., Caluseriu, O., Smith, A. C., Fei, Y. L., Nishikawa, J., Stockley, T. L., Best, L., Chitayat, D., Olney, A., Ives, E., Schneider, A., Bestor, T. H., Li, M., Sadowski, P., \& Squire, J. (2002). Discordant KCNQ1OT1 imprinting in sets of monozygotic twins discordant for Beckwith-Wiedemann syndrome. Human Molecular Genetics, 11, 1317-1325. 